\title{
Effect of ACTH on contralateral testicular damage and cytotoxic antisperm antibodies after unilateral testicular ischaemia in the rat
}

\author{
S. E. Kearney and D. I. Lewis-Jones \\ Department of Human Anatomy, University of Liverpool, Liverpool L69 3BX, U.K.
}

\begin{abstract}
Summary. Unilateral testicular ischaemia in the rat results in morphological damage in the contralateral testis (sympathetic orchiopathia). An increase in serum cytotoxic antisperm antibodies and serum IgM levels seen in this condition when compared to controls was reduced by daily i.m. administration of a synthetic adrenocorticotrophic hormone (ACTH) for 7 days. ACTH would appear to be acting as an immunosuppressant, possibly reducing the effect of this autoimmune condition on subsequent fertility.
\end{abstract}

\section{Introduction}

It is well established that certain types of infertility are immunologically mediated. Experiments on animals have shown that autoimmunity to spermatozoa, induced by immunization of the animal with isologous or autologous sperm antigen or testicular tissue, can result in infertility (Freund, Lipton \& Thompson, 1953; Johnson, 1970a). This autoimmunity can also affect seminiferous tubule architecture and function (Johnson, 1970b; Harrison, Lewis-Jones, Marval \& Connolly, 1981).

Kaya \& Harrison (1975) were the first to demonstrate that damage to the contralateral testis occurred after ipsilateral testicular ischaemia, a condition named sympathetic orchiopathia by Wallace, Gunter, Landon, Pugh \& Hendry (1982). Subsequent work has suggested that the damage is caused by an autoimmune phenomenon set up by the abnormal ischaemic testicular tissue but the mechanism of the response has still to be fully elucidated (Lewis-Jones, Marval \& Harrison, 1982; Cerasaro, Nachtsheim, Otero \& Parsons, 1984). An increase in serum cytotoxic antisperm antibodies has been demonstrated in animals suffering unilateral testicular ischaemia when compared to controls and there is also evidence of immunoglobulin breaching the blood-testis barrier and involving spermatogenic and supportive cells within the seminiferous tubules (Lewis-Jones et al., 1982).

The purpose of the present study was to investigate whether morphological damage within the contralateral testis and the titres of cytotoxic antisperm antibodies seen in such cases could be reduced by the administration of a synthetic adrenocorticotrophic hormone acting as an immunosuppressant.

\section{Materials and Methods}

Sexually mature albino male Wistar rats were chosen for the study and allocated to Groups A, B and $C ; 1$ of 3 inbred littermates was assigned to each group.

The 10 rats in each of Groups A and B were anaesthetized with ether. The abdominal cavity was opened and the vascular supply to the right testis was isolated and divided between two silk $5 / 0$ sutures above its anastomosis with the deferential vessels. A vasectomy was also performed and this 
divided vessels running with the vas deferens. After the operation the rats in Group A received daily intramuscular injections of $\mathrm{ACTH}_{1-24}$ (Synacthen Depot: CIBA Laboratories, Horsham, West Sussex, U.K.) at a dose of 0.5 international units $/ 100 \mathrm{~g}$ body weight, while the rats in Group B received injections of saline $(9 \mathrm{~g} \mathrm{NaCl} / \mathrm{l})$ in similar volumes. The 10 rats in Group $\mathrm{C}$ were also anaesthetized and the vascular bundle to the right testis was isolated and manipulated but not interrupted. These animals also received daily i.m. injections of saline.

After 7 days the animals were killed, the left testis removed from each animal and immersed in Bouin's fixative. Blood was obtained before death from each animal by cardiac puncture and serum samples stored at $-20^{\circ} \mathrm{C}$ until required.

Assessment of testicular damage. Testicular tissue was embedded in paraffin wax and sections were cut at $8 \mu \mathrm{m}$ from the equatorial and rete testis regions, at least 4 sections being taken from each region. Sections were stained with haematoxylin and eosin.

A Johnsen count was then performed on each section: at least 200 seminiferous tubules were examined and graded out of 10 as to their stage of spermatogenesis (Johnsen, 1970).

Cytotoxic antisperm antibody test. Heat-inactivated serum from animals in all groups was serially diluted in two volumes of diluent (45\% Medium 199, 45\% Hanks solution, $5 \%$ fetal calf serum and $5 \%$ phosphate buffer, $\mathrm{pH} 7 \cdot 2$ ). To each dilution of serum was added one volume of complement (fresh guinea-pig serum diluted 1 in 5) and one volume of normal rat spermatozoa obtained from the epididymal tail of rats from the same inbred stock (Johnson, 1970a). The dilutions were incubated at $37^{\circ} \mathrm{C}$ for $30 \mathrm{~min}$ and then scored for the percentage of live spermatozoa evaluated by eosin penetration (Boyce, Old \& Chouroulinkov, 1964). Results were obtained by two observers working simultaneously through the same dual-headed microscope. The cytotoxic effect of serum without complement, complement and no serum, and diluent only upon normal rat spermatozoa represented the control values.

Serum immunoglobulin assay. The amounts of IgM, IgG and IgA in the serum samples from all animals were measured by single radial immunodiffusion (Mancini, Carbonara \& Heremans, 1965). Samples were tested in duplicate on each of 2 separate immunodiffusion plates at 3 different dilutions. Goat antisera to IgA and IgM and a rabbit antiserum to IgG (Nordic Immunological Laboratories, Maidenhead, Berks., U.K.) were used. A rat reference serum (Serotec, Bicester, Oxon, U.K.) was used as a standard for IgA and IgM and purified rat IgG standard (Sigma Chemicals, Poole, Dorset, U.K.) was used for IgG estimations.

\section{Results}

\section{Assessment of testicular damage}

Table 1 shows that in the equatorial region of the testis, the Johnsen count in the Group B animals was lower than in those in Groups $C$ and A. The mean Johnsen count in Group B animals was significantly lower than in Group C (Table 1). There was no significant difference in Johnsen counts for rats in Group A and those in Group C, indicating that ACTH had reduced histological damage. There was, however, no significant difference between the Johnsen counts of rats in Groups B and A. A similar pattern of results was seen in the rete testis region (see Table 1); while the difference in counts between Groups B and C was not as marked, it was still significant.

\section{Cytotoxic antisperm antibody test}

As shown in Table 2, at all dilutions of test sera the percentage of live spermatozoa remaining after treatment with the sera from animals in Group $C$ was significantly higher than in those in Group B: ipsilateral testicular ischaemia appeared to cause a rise in the cytotoxicity of a rat's serum 
Table 1. The Johnsen counts, evaluated by histological investigations of two regions of the testis from rats in Group A (ischaemia + ACTH), Group B (ischaemia) and Group C (sham-operated control)

\begin{tabular}{|c|c|c|c|c|c|c|}
\hline \multirow[b]{2}{*}{ Litters $\uparrow$} & \multicolumn{3}{|c|}{ Equatorial region of testis } & \multicolumn{3}{|c|}{ Rete testis } \\
\hline & Group A & Group B & Group C & Group A & Group B & Group C \\
\hline 1 & 7.65 & $7 \cdot 61$ & 7.76 & 7.84 & $7 \cdot 82$ & 7.76 \\
\hline 2 & 8.03 & 7.93 & $8 \cdot 13$ & 7.35 & 7.65 & $7 \cdot 71$ \\
\hline 3 & 8.4 & 7.87 & $8 \cdot 1$ & 7.53 & 7.60 & 7.66 \\
\hline 4 & 7.99 & 7.98 & 8.06 & $7 \cdot 42$ & 7.51 & 7.64 \\
\hline 5 & 7.73 & $7 \cdot 77$ & 7.99 & $7 \cdot 41$ & 7.46 & 7.51 \\
\hline 6 & 7.69 & 7.72 & 7.74 & $7 \cdot 57$ & 7.49 & $7 \cdot 50$ \\
\hline 7 & $7 \cdot 72$ & 7.82 & 7.79 & $7 \cdot 45$ & 7.41 & 7.54 \\
\hline 8 & $7 \cdot 8$ & $7 \cdot 62$ & 7.65 & 7.62 & $7 \cdot 57$ & $7 \cdot 71$ \\
\hline 9 & 7.69 & $7 \cdot 71$ & 8.0 & 7.59 & $7 \cdot 47$ & $7 \cdot 50$ \\
\hline 10 & $7 \cdot 54$ & $7 \cdot 52$ & $7 \cdot 73$ & $7 \cdot 31$ & $7 \cdot 39$ & $7 \cdot 42$ \\
\hline Mean & $7 \cdot 82$ & $* 7.75$ & $* 7.89$ & $7 \cdot 54$ & +7.53 & +7.57 \\
\hline \pm s.d. & \pm 0.24 & $\pm 0 \cdot 14$ & \pm 0.17 & $\pm 0 \cdot 16$ & \pm 0.12 & \pm 0.1 \\
\hline
\end{tabular}

* $P<0.005 ; \dagger P<0.05 ;$ (Student's $t$ test).

$\dagger$ Each litter contributed 1 rat to each group.

Table 2. The mean percentage of live spermatozoa remaining after treatment with different dilutions of the test sera from rats in Group A (ischaemia + ACTH), Group B (ischaemia) and Group C (sham-operated control)

\begin{tabular}{lccc}
\hline Serum dilution & Group A & Group B & Group C \\
\hline $1 / 384$ & $68 \cdot 8^{\mathrm{a}}$ & $25 \cdot 0^{\mathrm{b}}$ & $63 \cdot 7^{\mathrm{a}}$ \\
$1 / 792$ & $56 \cdot 8^{\mathrm{a}}$ & $24 \cdot 9^{\mathrm{b}}$ & $49 \cdot 2^{\mathrm{a}}$ \\
$1 / 96$ & $45 \cdot 3^{\mathrm{c}}$ & $25 \cdot 6^{\mathrm{d}}$ & $51 \cdot 1^{\mathrm{c}}$ \\
$1 / 48$ & $38 \cdot 8^{\mathrm{c}}$ & $19 \cdot 9^{\mathrm{d}}$ & $33 \cdot 8^{\mathrm{c}}$ \\
$1 / 24$ & $36 \cdot 8^{\mathrm{g}}$ & $18 \cdot 2^{\mathrm{b}}$ & $31 \cdot 0^{\mathrm{z}}$ \\
$1 / 12$ & $30 \cdot 7^{\mathrm{i}}$ & $22 \cdot 9^{\mathrm{j}}$ & $29 \cdot 7^{\mathrm{eh}}$ \\
$1 / 6$ & $31 \cdot 6^{\mathrm{e}}$ & $15 \cdot 0^{\mathrm{f}}$ & $32 \cdot 4^{\mathrm{e}}$ \\
$1 / 3$ & $26 \cdot 0^{\mathrm{k}}$ & $18 \cdot 8^{\mathrm{i}} \mathrm{a}$ & $30 \cdot 7^{\mathrm{j}}$ \\
\hline No. of samples & 10 & 10 & 10 \\
\hline
\end{tabular}

a-b, $P<0.0005$; c-d, $P<0.005$; e f, $P<0.01$; h,$P<0.0125$; $\mathrm{i}-\mathrm{j}, P<0.025 ; \mathrm{k}-\mathrm{l}, P<0.05$ (Student's $t$ test).

Table 3. The mean immunoglobulin values in serum of rats in Group A (ischaemia + ACTH), Group B (ischaemia) and Group C (sham-operated control)

\begin{tabular}{lccc}
\hline & \multicolumn{3}{c}{$\begin{array}{c}\text { Immunoglobulin concentration } \\
\text { (mg/100 ml serum) }\end{array}$} \\
\cline { 2 - 4 } & Group A & Group B & Group C \\
\hline IgA & $7.00 \ddagger$ & $6.95^{*}$ & $8.85^{*} \ddagger$ \\
IgG & $1183.50^{*}$ & $1004 \cdot 00$ & $932.40^{*}$ \\
IgM & $78.05 \dagger$ & $89 \cdot 27 \dagger \ddagger$ & $71.05 \ddagger$ \\
\hline No. of samples & 10 & 10 & 10 \\
\hline $\begin{array}{l}\text { Within rows: } \\
\text { test). }\end{array}$ - $P<0.05 ; \ddagger P<0.025 ;$ & $* P<0.01$ & (Student's $t$
\end{tabular}


to spermatozoa. There was similarly a significant difference in the percentage of live spermatozoa after treatment with sera from Group A rats and Group B rats but no significant difference in results for Groups $\mathrm{A}$ and $\mathrm{C}$.

Controls, which included diluent and spermatozoa or diluent, complement and spermatozoa resulted in 61.3 and $57.6 \%$ sperm viability and those for tests with diluent, spermatozoa and heat-inactivated serum from rats in Groups A, B and C were $58.9,61 \cdot 7$ and $60.0 \%$ respectively (overall mean \pm s.d. $=60 \pm 16 \cdot 4 \%$ ).

\section{Serum immunoglobulin assay}

As seen in Table 3, IgM concentrations were significantly higher in Group B animals than in those in Groups $\mathrm{C}$ and $\mathrm{A}$. The IgG concentrations were markedly elevated in Group A rats compared to those in Group C. IgA concentrations were significantly lower in rats in Groups A and B than in those in Group C.

\section{Discussion}

This study has confirmed that unilateral testicular ischaemia in the rat (Group B) causes contralateral testicular damage in the form of suppressed spermatogenesis and also causes the production of cytotoxic antisperm antibodies. An elevation in IgM concentrations and a small increase in IgG values were also observed. Administration of ACTH after unilateral testicular ischaemia (Group A) reduced the degree of damage in the contralateral testis, although not preventing it completely. A reduction in titres of cytotoxic antisperm antibodies and IgM concentrations in the sera when compared to controls was also seen, suggesting that ACTH in such a situation is acting as an immunosuppressant. No cellular response was observed in the contralateral testis and therefore ACTH would not appear to be acting as an anti-inflammatory agent.

In normal circumstances the blood-testis barrier (Setchell \& Waites, 1975) prevents immunological sensitization by testicular tissue. Testicular ischaemia causes necrosis of the testis, and antigenic material within it, be it ischaemic or otherwise, would be presented to the immune system due to a breakdown of the blood-testis barrier. In the rat there are naturally occurring serum cytotoxic antisperm antibodies and these have been implicated in immunologically mediated testicular damage after testicular arterial ligation or sensitization with autologous testicular tissue (Harrison et al., 1981). There is an increase in the titres of serum cytotoxic antisperm antibodies after unilateral testicular ischaemia, and it is at present unclear whether this increased cytotoxicity is due to an increase in the quantity of naturally occurring cytotoxic antisperm antibody or whether there has been a change in specificity of that antibody. Whether the serum cytotoxic antisperm antibodies are responsible for the spermatogenic impairment in the contralateral testis is similarly unclear, because a separate antibody may have been produced which is directed against cells maintaining the blood-testis barrier and/or spermatogenic cells. Such antibodies may be able to penetrate the blood-testis barrier of the contralateral testis, subsequently damaging it and then gain access to the contents of the seminiferous tubule, possibly affecting subsequent fertility. There is no evidence of a cellular reaction involving the blood-testis barrier but the possibility of other factors affecting it, such as sensitized lymphocytes and lymphokines, should be considered.

From the results of the immunodiffusion experiments, it seems likely that the cytotoxic antisperm antibodies and the antibodies causing contralateral testicular damage are of the IgM class and probably represent a primary immune response which has been activated by the exposure of the immune system to ischaemic testicular tissue. A slight elevation in IgG values, although not significant when comparing the ischaemic group animals with controls (Groups B and C), may represent the start of the secondary immune response. 
This experiment was performed to mimic torsion of the testis in the human, after which fertility is known to be impaired (Krarup, 1978; Bartsch, Frank, Marberger \& Mikuz, 1980; Thomas \& Williamson, 1983; Thomas, Cooper, Smith, Lee \& Williamson, 1984). It is suggested that, after torsion, not only will the testis be severely damaged, but the contralateral testis will also be damaged via an autoimmune phenomenon. Cytotoxic antibodies produced in response to the torsion (Lewis-Jones et al., 1982; Cerasaro et al., 1984; Thomas et al., 1984) would also adversely affect sperm function and therefore impair fertility.

The results of this work suggest that, if testicular torsion is suspected, the testis should be examined following scrototomy for macroscopic signs of necrosis, however viable or non-viable the testis was thought to be clinically at presentation. If found to be viable, and showing only early signs of ischaemia, it should be untwisted and then tethered, and a similar tethering operation should be performed on the contralateral side. If non-viable and completely necrotic, it should be removed and a tethering procedure performed on the contralateral side (Harrison et al., 1981). Because ischaemia will have occurred in the twisted testis, whether the outcome is tethering and salvage, or orchidectomy, the results of this study would suggest that all cases might benefit from immunosuppression, possibly using ACTH. Autoantibody production may thus be reduced, and this might improve the subsequent fertility status of a patient who has suffered testicular ischaemia. It has also been suggested that an autoimmune reaction might follow testicular damage (LewisJones et al., 1982; Wallace et al., 1982) in cases of physical trauma or orchitis, and such cases might also benefit from immunosuppression.

We thank E. Joughin and I. Davies for technical assistance and CIBA Laboratories for generously supplying Synacthen Depot.

\section{References}

Bartsch, G., Frank, St., Marberger, H. \& Mikuz, G. (1980) Testicular torsion: late results with special regard to fertility and endocrine function. $J$. Urol. 124, 375-378.

Boyce, E.A., Old, L.J. \& Chouroulinkov, I. (1964) Cytotoxic test for demonstration of mouse antibody. In Methods in Medical Research, Vol. 10, pp. 34-37. Ed. H. N. Elsen. Year Book Medical Publishers, Inc., Chicago.

Cerasaro, T.S., Nachtsheim, D.A., Otero, F.E. \& Parsons, C.L. (1984) The effect of testicular torsion on contralateral testis and the production of antisperm antibodies in rabbits. $J$. Urol. 132, 577-579.

Freund, J., Lipton, M.M. \& Thompson, G.E. (1953) Aspermatogenesis in the guinea pig induced by testicular tissue and adjuvants. $J$. exp. Med. 97, 711-725.

Harrison, R.G., Lewis-Jones, D.I., Marval, M.J. \& Connolly, R.C. (1981) Mechanism of damage to the contralateral testis in rats with an ischaemic testis. Lancet 2, 723-725.

Johnsen, S.G. (1970) Testicular biopsy score count. A method for registration of spermatogenesis in human testes: normal values and results in 335 hypogonadal males. Hormones 1, 2-25.

Johnson, M.H. (1970a) Changes in the blood-testis barrier of the guinea-pig in relation to histological damage following iso-immunization with testis. $J$. Reprod. Fert. 22, 119-127.

Johnson, M.H. (1970b) Selective damage to spermatogenic cells at high antigenicity during auto-allergic aspermatogenesis. J. Path. 102, 131-138.
Kaya, M.R. \& Harrison, R.G. (1975) An analysis of the effects of ischaemia on testicular ultrastructure. $J$. Path. 117, 105-117.

Krarup, T. (1978) The testis after torsion. Br. J. Urol. $\mathbf{5 0}$, $43-46$.

Lewis-Jones, D.I., Marval, M.J. \& Harrison, R.G. (1982) Impairment of rat spermatogenesis following unilateral experimental ischaemia. Fert. Steril. 38, $482-490$.

Mancini, G., Carbonara, A.O. \& Heremans, J.F. (1965) Immunochemical quantitation of antigens by single radial immunodiffusion. Immunochemistry 2 , 235-254.

Setchell, B.P. \& Waites, G.M.H. (1975) The blood-testis barrier. In Handbook of Physiology, Vol. 5, pp. 143-172. Eds D. W. Hamilton \& R. O. Greep. American Physiological Society, Washington, D.C.

Thomas, W.E.G. \& Williamson, R.C.N. (1983) Diagnosis and outcome of testicular torsion. Br. J. Surg. 70, 213-216.

Thomas, W.E.G., Cooper, M.J., Smith, J.H.F., Lee, G. \& Williamson, R.C.N. (1984) Sympathetic orchiopathia following acute testicular torsion. Br. J. Surg. 71, 380 .

Wallace, D.M.A., Gunter, P.A., Landon, G.V., Pugh, R.C.B. \& Hendry, W.F. (1982) Sympathetic Orchiopathia-an experimental and clinical study. Br. J. Urol. 54, 765-768. 